\title{
THE ECONOMIC AND PSYCHO-SOCIAL EXPERIENCES AND COPING RESOURCES OF FAMILY MEMBERS CARING FOR PEOPLE LIVING WITH AIDS IN THEIR HOMES IN BHAMBAYI, KWAZULU-NATAL, SOUTH AFRICA
}

\section{Tanusha Raniga, Siphiwe Motloung}

\section{BACKGROUND LITERATURE ON FAMILY MEMBERS CARING FOR PERSONS WITH AIDS}

There is empirical evidence that families have responded with much resilience and compassion to caring for persons living with AIDS (PWAs) in their homes (Engelbrecht \& Kasiram, 2007; Sekokotla \& Mturi, 2004; Simpson \& Raniga, 2004). At the same time families in poverty-stricken communities are increasingly struggling and failing to provide optimally for the economic and psycho-social needs of PWAs who are in their care (Bartlett \& Finkbeiner, 2006; Darling, Olmstead \& Tiggleman, 2009). It is not surprising, however, at a time when the devastating effects of HIV and AIDS are all too evident, that international organisations, national governments and civil society organisations recognise the invaluable role played by extended family members as support caregivers in the care of those terminally ill with AIDS.

In South Africa there are between 1500 and 1700 new infections a day and approximately 5.7 million people living with HIV (UNAIDS, 2008). As HIV testing and the roll-out of antiretroviral therapy programmes are scaled up, many public hospitals are full to capacity and those persons terminally ill with AIDS are sent back home to be cared for by family and/or significant others (Van Dyk, 2005). In fact, it is widely acknowledged that persons living with HIV and AIDS and their support persons experience stress associated with AIDS-related complications and caregiver responsibilities (Darling et al., 2009; Raniga \& Simpson, 2010; Van Dyk, 2005). Particularly in low-income communities such informal caregiving can be stressful and has social, economic, medical and psychological implications for both family members and PWAs (Darling et al., 2009; Newman, Fogarty, Makoae \& Reavely, 2011; Raniga \& Simpson, 2010). People living with AIDS experience physiological symptoms such as a decrease in weight and energy levels, frequent fevers, rashes, increasing loss of memory and secondary infections such as tuberculosis (Van Dyk, 2005). The psychological implications include fear of early death which may lead to depression and despair, prejudice, and rejection by loved ones and the wider community (Van Dyk, 2005). However, as a result of deteriorating physical health PWAs experience the added stresses of ensuring compliance with antiretroviral treatment, and dealing with the fear of ridicule and stigma when having to reveal their diagnosis to family and community members. At the same time, social support from friends, family and partners has been found to be related to PWAs' ability to master AIDS-related stress (Darling et al., 2009), but may only be beneficial when perceived as satisfactory. 
It is also important to consider that many family members who are caregivers to PWAs also face intense levels of stress in the physical, economic and social spheres of their lives as a result of intolerable care demands (Darling et al., 2009). In fact, Powell-Cope and Brown (1992) mention that social rejection associated with caring for individuals with AIDS as well as psychosocial factors such as the length of time in the caregiver role, the number and severity of the PWAs' illnesses and the PWAs' depression may contribute to their own decreased health. Taking these issues into account, this study was a qualitative attempt to understand the economic and psycho-social experiences as well as the coping mechanisms of nineteen family members who were caring for PWAs in their homes in the predominantly low-income community of Bhambayi, KwaZulu-Natal. A central focus of this paper is the profound impact of socio-economic and gender factors on caregiving roles, responsibilities and coping mechanisms of family members caring for PWAs. Drawing on the practice elements embedded in structural theory, the paper concludes with some remarks concerning improvement of services at both micro and macro levels.

\section{STRUCTURAL CHALLENGES FACING FAMILIES CARING FOR PWAS}

Dominelli (2004) aptly contends that neoliberalism, globalisation and corporate managerial strategies have translated into high rates of poverty and inequality in contemporary society. Sewpaul (2005) adds that economic globalisation, with its dominant neoliberal orientation, has had a detrimental impact on families and communities in developing countries. The era of HIV and AIDS brings to the fore such structural imbalances and problems evident in contemporary South Africa. On a daily basis social workers grapple with the dilemmas of how best to provide personal and interpersonal help to children living with HIV and their families, as many of the issues and problems that they face are rooted in structural inequalities (Govender, 2009). Moreover, many feminist writers have argued that gender inequality, economic hardship and poverty are factors that contribute to sexual exploitation and violence against women in Africa (Bhana, 2009; Sewpaul, 2006). In a qualitative study with fifteen adolescent mothers Raniga and Mathe (2011) concluded that high rates of poverty and inequality in Bhambayi placed young African women in the vulnerable position of having to engage in risky behaviour such as transactional sex with older men in the community.

It is in the light of this situation that structural social work theory formed the conceptual foundation for this study. This theory draws from both the radical structuralist and radical humanist schools of thought that recognises the interconnection between peoples' private troubles and public issues that are beyond that immediate scope of influence (Dominelli, 2002; Mullaly, 1993; Sewpaul 2005).

Seventeen years into the new democracy South Africa remains a world of sharp socioeconomic and political contrasts and duality (Gray, 2006; Triegaardt, 2009). While many South Africans have witnessed rapid technological and economic advances, such gains have also come with mass job losses, privatisation of basic services, and progressive cuts in spending for welfare programmes, education, health and social 
security (Holscher, 2008; Raniga, 2006; Triegaardt, 2009). Proponents of social democratic thinking argue that a key feature and consequence of globalisation and neoliberal policies is deeper levels of poverty and inequality (Desai, 2007; Gray, 2006; Holscher, 2008; Sewpaul \& Holscher, 2004). In fact, writers such as Sewpaul (2005), Frye (2007) and Triegaardt (2009) state that the deepening levels of unemployment and poverty, coupled with the state's failure to deliver basic services can be traced to the conservative macro-economic policy of Growth, Employment and Redistribution (GEAR) introduced between 1996 and 2000. Consequently, Gow and Desmond (2002), Bartlett and Finkbeiner (2006), and Sekokotla and Mturi (2004) add that the declining productivity of breadwinners not only strains economic resources within households, but also the psycho-social and emotional relationships between family members acting as caregivers and PWAs. Using qualitative methodology, this research took into account structural factors such as socio-economic conditions and notions of gender essentialism that impact on the experiences of family caregivers of PWAs living in the impoverished community of Bhambayi.

\section{METHODOLOGY}

The University of KwaZulu-Natal: Community Outreach and Research Unit, located in the School of Social Work since 1992, has facilitated a student training unit in the Bhambayi community, where counselling services, group work programmes and community projects have been implemented by both students and academics. Baines (2007) states that critical social work involves a commitment not just to understanding the complex socio-political and economic problems evident in communities, but also the imperative to engage service users in transformative change. Bearing this in mind, positive networking relationships with the local community civic structure (Bhambayi Reconstruction and Development Forum) culminated in a research partnership in 2007, when three academics from the School of Social Work and Community Development, four community members and four final-year social work students who undertook to investigate the effects of poverty and HIV and AIDS on households. Ethical clearance was obtained in June 2007 from the Research Committee of the University of KwaZuluNatal to conduct the study. Phase one of the study comprised a 351 household-based survey, which illustrated that more than half of the older people in the community did not have adequate food and that $60 \%$ of those who did not receive the state old-age pension went hungry (Raniga \& Simpson, 2011). The empirical data presented in this paper entails the analysis of a sub-set of data from the qualitative phase of the larger study which aimed to:

- identify the psycho-social stressors of family caregivers caring for PWAs in their homes;

- understand the economic stressors associated with caregiving;

- gain insight into their coping strategies. 


\section{The research setting}

Bhambayi is a mixed formal/informal settlement located in the Inanda region, $35 \mathrm{~km}$ north of the Durban city centre. While the majority of residents have lived in the area for more than 20 years, the past decade has seen an influx of people from the Eastern Cape and neighbouring African countries such as Mozambique, Zimbabwe and Kenya. This in-migration has contributed to deeper levels of poverty and unemployment, and there is a clear need for integrated anti-poverty intervention strategies. There is very little infrastructure and few services available in the community. The Inanda Department of Social Development's social workers visit the community twice a month and the Provincial Department of Health operate a mobile clinic every Monday. The Siyathuthuka crèche provides early childhood educare services to approximately 120 children and the Siyazama support group provides psycho-social services to about 45 older folk in the community. The Department of Social Work, UKZN students and academics have for the past 15 years provided consistent and much valued social work services to residents in Bhambayi. The majority of the residents in Bhambayi speak isiZulu.

\section{Methodology and design}

In order to address the three core research objectives indicated above, an exploratory, descriptive design was employed. According to Rubin and Babbie (2009:134), exploratory, descriptive design is concerned "with conveying what it's like to walk in the shoes of people being described - providing rich details about their environments, interactions, meanings and everyday lives". This approach afforded family caregivers the opportunity to speak authoritatively about their experiences of caring for PWAs living in their homes. The researchers were concerned with how these participants make sense of their lived experiences taking into account the structural socio-economic and gender factors that impact on living in an impoverished community such as Bhambayi and caring for PWAs in their homes (Dominelli, 2002).

\section{Sampling process}

As applicable to qualitative methodology, the researchers employed non-probability purposive sampling to select the family caregivers of PWAs from the community. Sarantakos (2005) maintains that a limitation of non-probability sampling is that it does not ensure representation as it is not based on statistical randomness and thus cannot be generalised. The researchers networked with the Provincial Department of Health's Voluntary Counselling and Testing Site (VCT) in Bhambayi in order to obtain access to the intake register of those families who were affected by HIV and AIDS and were receiving home-based care and material resources from this project. A letter detailing the research process and its purpose was given to the Project Manager and a follow-up meeting was held with home-based care workers who worked in the VCT project for the purposes of identification of participants from the case records. As stated by Terre Blanche, Durrheim and Painter (2006), availability or convenience sampling comprises recruiting participants from places where they are easily accessible. The criteria for inclusion in the sample for the study were as follows: 
- Family members who were caring for PWAs in their homes and who were registered clients with the VCT project in Bhambayi;

- Persons living with AIDS who were receiving home-based care services from the VCT project in Bhambayi.

Babbie and Mouton (2001) aptly note that a specific sampling size cannot be determined at the outset of the study; instead the number of participants in the sample will be based on data saturation, i.e. when the information collected becomes repetitive. Bearing this in mind, the researchers obtained the identifying particulars of nineteen family caregivers of PWAs from the case registers and then made contact with them by means of home visits. During this contact the purpose and objectives of the research and their willingness to participate in the study were ascertained. Ethical issues such as confidentiality, recording and reporting of the data were discussed and clarified (Terre Blanche et al., 2006). A follow-up appointment was made with the participants to conduct the semi-structured interviews at a neutral venue, namely the interview rooms at the VCT clinic. Interviews were conducted in isiZulu by the researchers and permission was sought to take detailed field notes to record the participants' verbal and non-verbal responses. The advantage of the interactive in-depth interview was to give the researchers an opportunity to establish a relationship with the participants and to ensure that they were equal partners in the research process (Baines, 2007). In so doing, the researchers adopted a dual role as empathic listener, providing de-briefing and support when necessary, and as "observer and minimal participant", interacting casually during the interview process (Morris, 2006). The average duration of the interview sessions was 1.5 hours.

\section{Data collection and data analysis}

Data were collected from the family caregivers by means of semi-structured interviews with the aid of an interview guide (Terre Blanche et al., 2006). Qualitative interviews include interaction between the interview and participants where the interviewer establishes a purposeful direction with the aim of understanding the perspectives of the persons being interviewed (Babbie \& Mouton, 2001). This is complementary to Baines's (2007:22) suggestion for structural social justice researchers to be "flexible, emergent and iterative throughout the research process". As such there was ongoing mutual negotiation of meaning and power among the researchers and the family caregivers. Terre Blanche et al. (2006) explain that a semi-structured interview is conducted by using open-ended questions that are contained in an interview guide with a focus on the overall objectives of the study. The following questions were used as a guide in the interview process with the family caregivers:

- What is the demographic profile of family members and PWAs?

- What are the psycho-social stressors experienced by family members?

- What are the economic challenges experienced by family members?

- What are the coping strategies of family members? 
The advantage of the interviews was that they provided the participants with room to answer in their own terms, avoiding bias and providing extensive, in-depth information on caregiver responsibilities and challenges of caring for PWAs in their homes.

The detailed interview transcripts were translated from IsiZulu to English. One of the researchers who was well versed in isiZulu checked whether the English translations of the interview were in fact what had been said in isiZulu. It is, however, vital to acknowledge that some meaning may have been lost from the translation of the field notes and transcripts from isiZulu to English. Subsequently, the data analysis commenced by creatively adopting Kvale's (1996) process of examining, categorising, tabulating and recombining the data to address the core objectives of the study. Terre Blanche et al. (2006) make an important point that the process of moving from data capturing to conceptualisation and theorisation is the most tedious yet distinguishable aspect of qualitative research.

Five important themes emerged from the data analysis which form the central premise of the results and discussion below: biographical profiles of participants; biographical profile of PWAs and their relationship to the caregiver; psycho-social stressors; harsh economic conditions; and coping strategies. In the interpretation of the findings the researchers were mindful that understanding the family members' roles as caregivers necessitates an understanding of the complex interplay of socio-economic and gender forces that profoundly impact on their lives (Dominelli, 2004).

\section{DISCUSSION OF RESULTS}

The findings presented emerged from the analysis of nineteen individual in-depth semistructured interviews conducted with family caregivers of PWAs as well as from field notes and meetings between researchers and the student social workers on the analysed data. The discussion on the findings will be presented in three sections:

- A biographical profile of the participants;

- A biographical profile of PWAs and their relationship to the family caregiver;

- A discussion of three inter-connected themes, namely, psycho-social stressors, harsh economic conditions, and coping strategies.

Table 1 provides the biographical profile of the research participants.

Four of the participants were aged 21-26 years, while 11 were between 30-39 and four were 40-47 ( $\mathrm{N}=19)$. Sixteen of the family caregivers were single, while two were married and one cohabiting with their partner as "common law wife". 
TABLE 1

BIOGRAPHICAL PROFILE OF THE PARTICIPANTS

\begin{tabular}{|c|l|l|l|l|l|}
\hline $\begin{array}{c}\text { Participant } \\
\text { number }\end{array}$ & Age & Gender & Marital status & $\begin{array}{c}\text { Employment } \\
\text { status }\end{array}$ & $\begin{array}{c}\text { Highest level of } \\
\text { education }\end{array}$ \\
\hline 1 & 47 & Female & Married & Unemployed & Grade 12 \\
\hline 2 & 32 & Female & Single & Unemployed & Grade 10 \\
\hline 3 & 42 & Female & Single & Unemployed & Grade 4 \\
\hline 4 & 36 & Female & Common Law Wife & Unemployed & Grade 2 \\
\hline 5 & 36 & Female & Married & Unemployed & Grade 7 \\
\hline 6 & 39 & Female & Single & Self employed & Grade 12 \\
\hline 7 & 23 & Female & Single & Unemployed & Grade 12 \\
\hline 8 & 23 & Female & Single & Unemployed & Grade 10 \\
\hline 9 & 26 & Female & Single & Unemployed & Grade 5 \\
\hline 10 & 36 & Female & Single & Unemployed & Grade 7 \\
\hline 11 & 38 & Female & Single & Unemployed & Grade 10 \\
\hline 12 & 39 & Female & Single & Unemployed & Grade 1 \\
\hline 13 & 37 & Male & Single & Self-employed & Grade 11 \\
\hline 14 & 40 & Male & Single & Unemployed & None \\
\hline 15 & 21 & Female & Single & Unemployed & Grade 12 \\
\hline 16 & 34 & Female & Single & Unemployed & Grade 2 \\
\hline 17 & 40 & Female & Single & Unemployed & None \\
\hline 18 & 38 & Female & Single & Self-employed & Grade 7 \\
\hline 19 & 37 & Female & Single & &
\end{tabular}

In this study 17 of the caregivers were female and two were male. Consistent with qualitative research with 25 caregivers in Lesotho undertaken by Newman et al. (2011), gender inequalities are particularly acute in HIV and AIDS caregiving, where older women and young girls bear the brunt of caring for the sick at home. Raniga and Simpson $(2010 ; 2011)$ argue that the status of black women in the country has not changed as they make up the majority of the informal, unpaid workforce and thus remain on the bottom rung of the social strata. Sixteen were unemployed and three were selfemployed. Only four of the participants completed secondary school, while five completed up to Grade 11; eight completed up to Grade 7 and two had never attended school. Bearing in mind the low literacy levels and the dominance of female caregivers as illustrated in Table 1, it is appropriate to argue that woman's nurturing and caregiving roles results in lost opportunities for education, career and income (Newman et al., 2011). Dominelli (2002) views such gendered identity as a central feature of internalised oppression and relates this to the difficulties associated with changing norms around the responsibilities and organisation of family caregiving. In fact, Newman et al. (2011:2) add that "at the heart of women's disproportionate and inequitable AIDS caregiving burden lies gender inequality". When viewed from this perspective, the unequal sharing of responsibilities between men and women in households results from - and is sustained by - the patriarchal institutional norms around the organisation of caregiving in families. Taking this into account, it was interesting to examine the biographical profile of the PWAs in order to understand the challenges facing the family caregivers. 
Table 2 indicates the biographical profile of PWAs and their relationship to the family caregiver.

\section{TABLE 2}

BIOGRAPHICAL PROFILE OF PWAS AND THEIR RELATIONSHIP TO THE FAMILY CAREGIVER

\begin{tabular}{|c|c|c|c|c|c|}
\hline Number & Age & Gender & $\begin{array}{l}\text { Relationship of family } \\
\text { caregiver to PWA }\end{array}$ & $\begin{array}{l}\text { Duration of PWA } \\
\text { residing in family } \\
\text { caregiver's home }\end{array}$ & $\begin{array}{c}\text { Duration of } \\
\text { PWA being } \\
\text { chronically ill }\end{array}$ \\
\hline 1 & 35 & Female & Daughter & 24 years & 13 years \\
\hline 2 & 56 & Female & Mother & 3 years & 2 years \\
\hline 3 & 32 & Female & Sister & 10 years & 2 years \\
\hline 4 & 40 & Male & Common-law husband & 10 years & 3 years \\
\hline 5 & 25 & Female & Sister in law & 3 years & 5 years \\
\hline 6 & 29 & Female & Sister & 29 years & 5 years \\
\hline 7 & 34 & Male & Not related & 2 years & 2 years \\
\hline 8 & 47 & Male & Father & 23 years & 5 years \\
\hline 9 & 29 & Female & Sister & 26 years & 3 years \\
\hline 10 & 41 & Female & Sister & 3 years & 2.5 years \\
\hline 11 & 39 & Male & Boyfriend & 2 years & 1.5 years \\
\hline 12 & 35 & Female & Sister & 2 years & 2 years \\
\hline 13 & 41 & Male & Brother & 7 years & 1.5 years \\
\hline 14 & 30 & Male & Uncle & 5 years & 1.5 years \\
\hline 15 & 39 & Female & Daughter & 21 years & 1 year \\
\hline 16 & 27 & Female & Sister & 1 year & 1.5 years \\
\hline 17 & 26 & Female & Mother & 26 years & 1 year \\
\hline 18 & 22 & Female & Mother & 22 years & 1 year \\
\hline 19 & 31 & Female & Cousin & 1 year & 1 year \\
\hline
\end{tabular}

Six of the PWAs were between the ages of 20-29, while eight were aged 30-39, four were 40-49 and one was over 50. The gender profile of the PWAs revealed that 13 females and 6 males made up the sample. It was interesting but not surprising that 15 of the family caregivers shared a kinship relationship, where the PWA was their sibling, child, parent or partner. Three of the participants indicated that the family caregiver was an extended family member, either their sister-in-law, uncle or cousin. One participant indicated that she was not related to the PWA, but he has been in her care for two years. These findings corroborate the conclusion in Darling et al. (2009) that one major method of PWAs coping with physiological and social changes was drawing on the social support of family, friends and partners. Raniga and Simpson (2010) also conclude from a qualitative study of 15 grandmothers who were caregivers to PWAs that the most important informal safety net in Bhambayi was neighbours and family. It is positive to note that despite times of economic hardships, the values of ubuntu in this community are commendably active, even though such support systems are at risk of not being sustainable in the long term. 


\section{Psycho-social stressors}

There is no doubt that persons providing support to PWAs experience increased psychosocial stress associated with their roles as caregivers (Darling et al., 2009; Sekokotla \& Mturi, 2004). Vosvick and Amey (2005) stated that PWA caregivers are usually unprepared for their caregiving responsibilities and the subsequent changes in their own lives. They add that several factors may influence the overall perception of psychosocial stressors including the length of time of the caregiving relationship, number and severity of PWA illness-related symptoms, behavioural problems and PWA depression. As illustrated in Table 2, PWAs lived an average of 12 years in their caregiver households. This long-term caring relationship may be perceived as a major contributing factor to caregiver stress.

Some of the comments of the female participants were:

"I have to be there if he wants to go to toilet because he can't lift himself in order to use the basket."

"I have to move her and even to change her and once she sleeps with her right side, she will remain like that if I don't turn her."

"It is stressful especially the fact that you can see the person is not getting any better."

Newman et al. (2011) revealed that women's greater responsibility for caring for PWAs results in greater physical, social and psychological stress. Sixteen of the participants indicated that they mainly experienced powerlessness, anger, depression and social rejection. Some of the participants' comments were:

"Having to care for a father, drop out of school because I couldn't cope is stressful and sometimes I cry, because I can't change the situation."

"I sometimes feel like I can't take it anymore because it is her fault that she is sick."

The common-law wife commented:

"I felt betrayed and lied to because he did not tell me his status until he got sick two years ago. If a person tells the truth from the beginning, it is easy to help each other rather than to lie and go to the wrong places for help."

"It is stressful, especially due to the fact that you can see that the person is not getting any better."

"It is very stressful because I don't tell anyone she has AIDS, so I have no one to help and to talk to about her condition."

Seventeen of the participants stated that stigmatisation and discrimination were the biggest problems associated with their caregiving role and that they preferred keeping the status of the PWA a secret. This had a ripple impact on their social life, as one participant stated:

"I don't socialise as I used to before the PWA became chronically ill." 
Another participant commented:

"I can no longer go to church because I cannot leave him with children and he is very sensitive when left alone."

Darling et al. (2009) revealed that secrecy is common to families of various cultures who are living and or caring for HIV-infected relatives. Newman et al. (2011) added that PWA support persons rely on "strong societal ties" and the minute they risk disclosing the HIV status of the PWA, "weak societal ties" emerge as some of the friends and neighbours start to keep a distance from them, making caregiving a difficult and exploitative responsibility.

\section{Harsh economic conditions}

Economic stress was the most frequent concern revealed by participants. Table 1 illustrates that 16 of the caregivers were unemployed and three reported that they were self-employed. During the interviews some of the caregivers became emotional when they explained that the economic circumstances under which they were expected to fulfil their responsibilities were unfair and harsh. The majority lacked access to basic services such as piped water, electricity, adequate caring space at home and thus privacy. Some said that:

"I have to rise early to fetch water from the communal taps and sometimes pay young children to go fetch other times in the day."

"On clinic days and when he is sick I have to pay for transport to take him for treatment and to fetch medication. This makes life even more difficult."

Others who were hiding the PWA's health status were forced to go to service providers who were from outside of the Inanda region for fear of being recognised by others in the community. This was economically demanding and triggered psychosocial difficulties and pain. Such stigma and discrimination as alluded to earlier made caregiving a very difficult activity.

All of the participants indicated that they were dependent on at least one state support grant. However, this was inadequate to meet the economic demands of care. This corroborates the experiences of grandmothers in receipt of the state old-age pension in Bhambayi, where $56.6 \%$ relied on the grant, which was not enough to sustain those in their care (Raniga \& Simpson, 2010). As some of the sentiments shared by mainly the female participants were:

"Caring for my sick father demands money as I have to buy special foods for him and medication every month and I had to give up my job to look after him."

"I have to buy nappies for my baby and my sick brother and the child support grant is not enough."

"It takes a lot of time to care for the sick and this leaves little time to earn money and provide for my family."

The above comments reflect that many of the caregivers had to give up their employment as a result of their caregiving responsibilities, while at the same time the economic demands 
were stressful. All of the participants added that the increases in food prices, the loss of economic support from the person infected, compounded by medical costs and caring for an average of six persons per household, were stressful. Triegaardt (2009) aptly mentions that after 1994 South Africa grappled with structural challenges such as economic globalisation, high debt incurred by the previous Nationalist government and the ripple effect of this on unemployment, poverty and inequality. It is important to bear in mind that almost seventeen years on, such factors continue to exacerbate the plight of the poor, especially those households caring for those infected with AIDS.

\section{Coping resources}

Darling et al. (2009) concluded from their survey of 114 PWAs and their support persons on their stress and life satisfaction that social services and health professionals need to be aware of the importance of family stress and coping strategies, as they influence the life satisfaction of PWAs and their support caregivers. Bearing the high levels of psycho-social stresses and harsh economic conditions that the family caregivers in this study were subject to, it was important to understand how they coped with their life situation. The majority of the participants spoke about being grateful for the home-based care workers who visited weekly to assist with household chores, bathing the PWA and administering medication. However, they also felt the need for more frequent visits, though this was difficult to arrange as a result of the limited human and financial resources of the VCT project in Bhambayi. Furthermore, only seven of the family caregivers (two of them being male) indicated that they received social and emotional support from extended family members and friends. The remaining twelve caregivers lacked social support to address their AIDSrelated caregiving stress. In fact, many spoke of higher levels of distress and delayed seeking health care for themselves, resulting in lack of awareness of the deterioration of their own health, particularly if they became isolated from support systems such as friends and family. As one female caregiver commented:

"I am always tired and don't sleep well at night and there is no one I can turn to help me with my own health problems."

However, what was encouraging to hear in the interviews was the affection and deep sense of genuine care that the caregivers felt for the PWAs in their homes. One mother stated:

"I am very happy that I am caring for my child because I cannot leave him in the hospital to be cared by someone else while as I am here as her mother."

This is significant as Darling et al. (2011) contend that the way in which the PWAs perceive their social support impacts on their own coping levels. In this sense the PWA's dealing with AIDS-related stress is closely linked to the quality of care and the perceptions of their support persons.

Many of the family caregivers, however, mentioned the need for training and supportive services from social workers and health professionals to help with the demands of caregiving for PWAs. Attention must also be given to the economic demands of caregiving as this is a key contributing factor to the stress and poor life satisfaction of PWA family caregivers. 


\section{RECOMMENDATIONS AND CONCLUSIONS}

This study has shown that family caregivers perform a significant role in the care of people chronically ill with AIDS. The findings further illustrate that the psycho-social stressors and economic costs of PWA caregiving are extensive. Based on these data, interventions by health professionals and social workers to provide economic and psychosocial support could be hypothesised to improve both the quality of life of caregivers and PWAs (Darling et al., 2009; Raniga \& Simpson, 2010; Smith et al., 2010). It is important to bear in mind that a structural analysis emphasises not only changing the material conditions in society, but that consciousness-raising at a micro level is equally important (Mullaly, 1993). Mullaly (1993) proposes two fundamental approaches. First, at a micro level it is vital that the Department of Social Development and Health work together to provide counselling, establish support groups and increase home-based care services for caregivers caring for PWAs in their homes. Moreover, such increased infrastructure and networks in communities can serve as a platform to raise public consciousness on the psycho-social and economic burdens of AIDS caregiving which is a fundamental prerequisite for transforming society (Mullaly, 1993). It is also imperative that social workers engage caregivers in publicising both their personal suffering and the economic costs of AIDS caregiving, thereby lobbying policymakers for better planning for health and social services.

The findings also reveal that caregiving for PWAs is a gender-segregated responsibility, where "unpaid women's work in family structures is reproduced as unpaid care for others in the community" (Newman et al., 2011:8). This is not surprising as in subSaharan Africa gender inequalities are particularly acute in HIV and AIDS caregiving, where older women and young girls make up the unpaid, informal workforce (Newman et al., 2011). Many of the female caregivers in this study perceived the need to increase the number of male home-based care providers to deal with the heavy burdens of care. It is thus imperative that policymakers, activists and social and health professionals redress the persistent disadvantages faced by mainly female caregivers and the gendered economic, psychological and social rejection experienced in AIDS caregiving.

This study was limited to one low-income community, namely Bhambayi in KwaZuluNatal, and the findings thus cannot be generalised to other provinces in the country. Further qualitative research is therefore needed to examine the differences between male and female PWA support persons and the implications of caregiving. Furthermore, a quantitative longitudinal study across several provinces on the dynamics and economic complexities of family coping strategies is another approach to explore.

\section{REFERENCES}

BABBIE, E. \& MOUTON, J. 2001. The practice of social research. Cape Town: Oxford University Press South Africa.

BAINES, D. 2007. Doing anti-oppressive practice, building transformative politicized social work. Canada: Fenwood Publishing.

BARTLETT, J.G. \& FINKBEINER, A.K. 2006. The guide to living with HIV infection $\left(6^{\text {th }}\right.$ ed). United States of America: The John Hopkins University Press. 
BHANA, D. 2009. "They've got all the knowledge": HIV education, gender and sexuality in South African primary schools. British Journal of Sociology of Education, 30(2):165-177.

DESAI, A. 2007. Taylorism and Mbekism. Africanus, Journal of Development Studies, 37(2):272-287.

DARLING, C.A., OLMSTEAD, S.B. \& TIGGLEMAN, C. 2009. Persons with Aids and their support persons: stress and life satisfaction. Stress and Health, 26:33-44.

DOMINELLI, L. 2002. Anti-oppressive social work theory and practice ( $2^{\text {nd }}$ ed). New York: Palgrave MacMillan.

DOMINELLI, L. 2004. Social work: theory and practice for a changing profession. Cambridge: Polity Press.

ENGELBRECHT, C. \& KASIRAM, M. 2007. Assessing and serving families and communities responsibly: challenges posed in an urban, marginalised setting. South African Family Practice Journal, 49(9):4-8.

FRYE, I. 2007. The "second economy" as intellectual sleight of hand. Africanus, Journal of Development Studies, 37(2):175-190.

GOVENDER, V. 2009. The experiences of social workers in the provision of reconstruction services to HIV infected children. Durban: University of KwaZuluNatal. (Unpublished MA Thesis)

GOW, J. \& DESMOND, C. 2002. Impacts and interventions: the HIV/AIDS epidemic and the children of South Africa. Pietermaritzburg: University of Natal Press.

GRAY, M. 2006. The progress of social development in South Africa. International Journal of Social Welfare, 15(1):53-64.

HOLSCHER, D. 2008. The Emperor's new clothes: South Africa's attempted transition to developmental social welfare and social work. International Journal of Social Welfare, 15(1):114-123.

KVALE, S. 1996. Interviews: an introduction to qualitative research interviewing. United States of America: Sage Publications.

MORRIS, T. 2006. Social work research methods: four alternative paradigms. Thousand Oaks, CA: Sage Publications.

MULLALY, R. 1993. Structural Social Work. Toronto: McClellant and Stewart Inc.

NEWMAN, C.J., FOGARTY, L., MAKOAE, L.N. \& REAVELY, E. 2011. Occupational segregation, gender essentialism and male primacy as major barriers to equity in HIV/AIDS caregiving: findings from Lesotho. International Journal for Equity in Health, 10(24):1-13.

POWELL-COPE, G.M. \& BROWN, M.A. 1992. Going public as an AIDS family caregiver. Social Science and Medicine, 34(5):571-580. 
RANIGA T. 2006. The implementation of the National Life-skills and HIV/AIDS School Policy and Programme in the EThekwini Region. Durban: University of KwaZulu-Natal. (Unpublished PhD Thesis)

RANIGA, T. \& SIMPSON, B. 2010. Grandmothers bearing the brunt of HIV/AIDS in Bhambayi, KwaZulu-Natal South Africa. The Social Work Practitioner, 22(1):1-18.

RANIGA, T. \& SIMPSON, B. 2011. Poverty, HIV/AIDS and the old age pension in Bhambayi, KwaZulu-Natal South Africa. Development Southern Africa Journal, 28(1):75-85.

RUBIN, A. \& BABBIE, E.R. 2009. Research methods for Social Work $\left(7^{\text {th }}\right.$ ed). USA: Brookes/Cole, Cencage learning.

SARANTAKOS, S. 2005. Social research $\left(3^{\text {rd }}\right.$ ed). Palgrave: Macmillan.

SEKOKOTLA, D. \& MTURI, T. 2004. Effects of the HIV/AIDS epidemic on the South African families. Loyola Journal of Social Sciences, XVIII:189-211.

SEWPAUL, V. 2005. Structural social justice approach to family policy: critique of the Draft South African Family Policy. Social Work/Maatskaplike Werk, 41(4):310-322.

SEWPAUL, V. \& HOLSCHER, D. 2004. Social work in times of neoliberalism: a postmodern discourse. Pretoria: Van Schaik Publishers.

SIMPSON, B. \& RANIGA, T. 2004. Co-housing as a possible housing option for children affected by HIV/AIDS: evidence from informal settlements. Urban Forum, 15(4):365-379.

SMITH, C.E., PIAMJARIYAKUL, U., YADRICH, D.M., ROSS, V.M., GAJEWSKI, B. \& WILLIAMS, A.R. 2010. Complex home care: Part III - economic impact on family caregiver quality of life and patients' clinical outcomes. Nursing Economics, 28(6):393-414.

TERRE BLANCHE, M., DURRHEIM, K. \& PAINTER, D. 2006. Research in practice. Applied methods for social sciences. Cape Town: University of Cape Town Press.

TRIEGAARDT, J. 2009. Pursuing a social development agenda in the context of globalisation: a South African perspective. Social Work/Maatskaplike Werk, 45(1):1-10.

UNAIDS. 2008. Report on the Global AIDS Epidemic. Geneva: UNAIDS.

VAN DYK, A. 2005. HIVAIDS care and counselling: a multidisciplinary approach. Cape Town: Maskew Miller Longman (Pty) Ltd.

VOSVICK, M. \& AMEY, K.F. 2005. Stress, social support and depression in informal caregivers to people living with HIV/AIDS. Lome: Togo.

Dr Tanusha Raniga, Ms Siphiwe Motloung, School of Social Work and Community Development, University of KwaZulu-Natal, Durban, South Africa. 